\title{
PROSPECTS FOR IMPROVING THE METHODOLOGY OF STRATEGIC ENTERPRISE MANAGEMENT
}

\author{
Svitlana Faizova', Marina Ivanova², Tetiana Pozhuieva ${ }^{3}$
}

\begin{abstract}
The prospects and directions of improvement of the methodology for strategic enterprise management have been highlighted. The subject of the research is theoretical and methodological aspects of creating a strategic enterprise management system based on the concept of a Balanced Scorecard (BSC). It has been revealed that in the context of changing the concept of the enterprise strategic development toward the growth of its intellectual capital as the main factor of competitiveness, the evolution of the enterprise management and planning system from strategic enterprise management to balanced enterprise management is taking place. The balanced scorecard has been defined as the basic concept of balanced enterprise management. The purpose of the study is to outline the prospects and directions for improving the methodology of strategic enterprise management under the conditions of its evolution into balanced enterprise management. Results. On the basis of a mathematical representation of the sphere of strategic responsibility (SSR) of the enterprise as an organizational and infrastructural environment for balanced enterprise management, it has been proved that the interaction of the SSR content components results in a synergistic effect of its expansion. This, in turn, determines the necessity and possibility of distributing the company's SSR beyond its management and involving the initiative owners in the process of balanced enterprise management. Accordingly, the prospects for improvement of the strategic enterprise management methodology have been defined as an integration of strategic management systems, approaches, methods and the BSC with non-traditional eventological methods combined with the analytic hierarchy process. It has been proved that, from the standpoint of the eventology, subjective observations and the mathematical apparatus of the theory of random events allow identification of general statistical regularities of the probabilistic set distribution in various, including management, systems. From the standpoint of a balanced approach, the need for enriching the methodology of the BSC as a system of balanced enterprise management, using the eventological analysis, is being boosted by the need to take into account the growing number of random, multi-directional and seemingly unrelated factors in the management process. Methodology. The following research methods were used in the study: the expert assessment method, factor analysis - for the formation of the management panel of the BSC; the eventological scoring and analytic hierarchy process - for balancing and structuring key performance indicators (KPI), economic and mathematical methods - to analyse the SSRs of the enterprise as an organizational and infrastructural environment for balanced enterprise management; a critical analysis - to compare alternative approaches to the formation of the BSC. Value/originality. To achieve the purpose of the study, the BSC methodology has been presented as a system of balanced enterprise management. A methodical approach to balancing and structuring KPIs, using the results of eventological analysis and analytic hierarchy process, has been proposed. Its practical implications include the possibility of reaching the target balance of indicators taking into account weighing coefficients of the main indicator selection criteria, the possibility to determine the whole system balance index as the average of the balance indices of each of the indicators that characterize the enterprise performance. The ways of implementing the methods of e-scoring and analytic hierarchy process for the assessment and correction of the enterprise's strategy have been studied. Integration of e-scoring with the strategic enterprise management method and the BSC methodology provides an effective vertical communication as the basic principle of balanced enterprise management, which extends the scope of strategic responsibility to subordinate initiative owners.
\end{abstract}

Key words: strategic enterprise management, Balanced Scorecard, balanced scorecard methodology, methodology of eventological analysis, analytic hierarchy process.

JEL Classification: M10, M41, B41, B49, C13

\footnotetext{
Corresponding author:

${ }^{1}$ National Metallurgical Academy of Ukraine, Ukraine.

E-mail: faizova4444@gmail.com

${ }^{2}$ National Mining University, Ukraine.

E-mail:mariva@ukr.net

${ }^{3}$ Ukrainian State University of Chemical Technology, Ukraine.

E-mail: lowleyhome@ukr.net
} 


\section{Introduction}

With the advances of the economy, enterprises are changing the marketing orientation of their strategy toward the growth of their intellectual capital as the main factor of competitiveness. As a consequence, the strategic enterprise management is being increasingly focused on the management of intangible assets, and strategic enterprise management is going up to a qualitatively new level of development, i.e. to the level of balanced strategic management. Unlike strategic enterprise management as a system for developing and implementing a strategy in the interests of owners, management and clients, balanced management will be a system of managing a strategy for increasing the company's value from the standpoint of all groups of economic and managerial influence, through balancing all the aspects of the enterprise's activities. The basic concept of balanced enterprise management is the Balanced Scorecard (BSC). Alongside the change in the concept of strategic development, the BSC is being transformed from the strategic enterprise management tool into an integrated system of strategic enterprise management as a more complex economic system. Certain signs of such tendency have been noticed by both foreign (Ashworth, 2006; Martin, 2006) and domestic researchers (Ivakina, 2007). However, the existing studies deal mainly with subproblems of the evolution of the BSC-based strategic enterprise management, considering the BSC in a limited methodological format. Methodological aspects of forming a management panel of the company's metrics and self-diagnostics of the company's strategic potential as a necessary condition for the effective formation of its balanced management are imperfect and lack research. The development of methodological principles of the BSC in the process of formation of balanced enterprise management, integration of methodical approaches and tools of strategic enterprise management and the BSC, their enrichment with non-traditional methods are in focus. Accordingly, the purpose of the study is to generalize and develop scientific and methodological foundations, to develop a methodology for strategic enterprise management under the conditions of its evolution into balanced enterprise management, to outline the prospects and directions of its improvement. This involves considering the following issues: analysis of preconditions for the integration of the strategic management systems, approaches, methods and the BSC with non-traditional eventological approaches combined with analytic hierarchy process (AHP); definition of the BSC methodology as a balanced enterprise management system; analysis of the methodical foundations for the formation of a management panel of indicators using the methods of e-scoring and analytic hierarchy process; justifying their possible applications for the assessment and correction of the company's strategy.

\section{Preconditions for integrating the methodology of the eventological analysis with the methodology of balanced enterprise management}

The formation of balanced enterprise management implies the creation of an appropriate organizational and infrastructural environment, which we define as a sphere of strategic responsibility (SSR). The coordinate area of the SSR is represented in Figure 1 in a threedimensional coordinate system, where the mission, vision and strategy of the enterprise are the centre of the SSR; $x$ is strategic goals; $y$ is strategic competencies, that is, directions of activity, strategically important for the enterprise and corresponding to its CSFs (Critical Success Factors) / KPI (Key Performance Indicators); $z$ is strategic resources, tangible and intangible, including tools for the strategic enterprise management.

The sphere of strategic responsibility of radius $R$ with the centre at the origin can be mathematically represented as the second-order equation:

$$
x^{2}+y^{2}+z^{2}=R^{2} \text {. }
$$

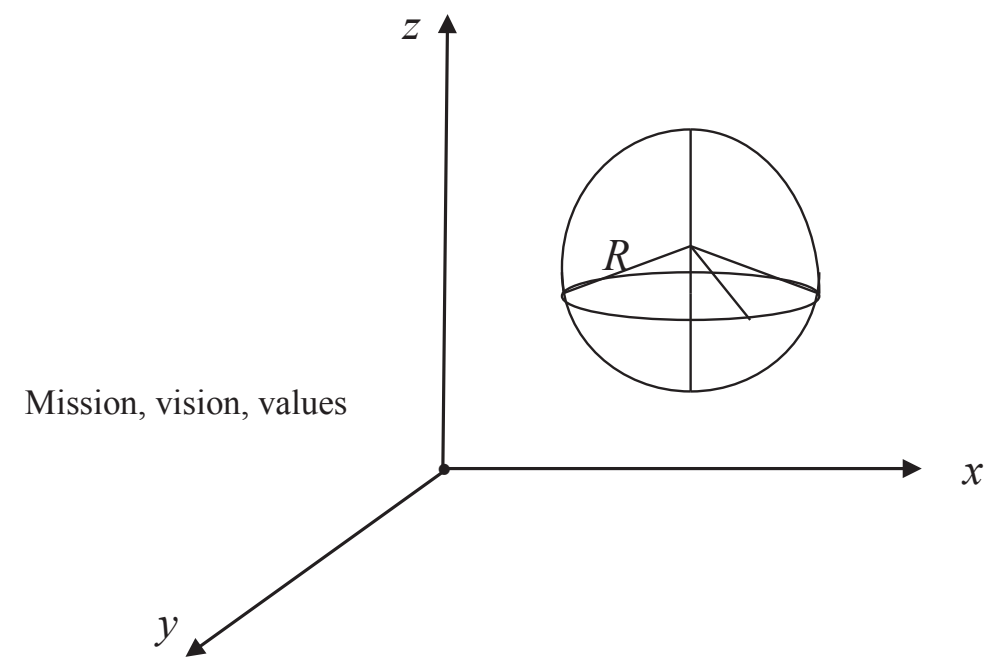

Figure 1. Coordinate area of the sphere of strategic responsibility 
Then the area of the SSR will be

$$
S C C B=4 \pi R^{2}=4 \pi\left[\left(x-x_{0}\right)^{2}+\left(y-y_{0}\right)^{2}+\left(z-z_{0}\right)^{2}\right] \text {, }
$$

where $\left(x_{0} y_{0} z_{0}\right)$ are the coordinates of the centre of the sphere of strategic responsibility.

Consequently, the interaction of the content components of SSR results in a synergistic effect of the expansion of the enterprise's SSR (with a coefficient $4 \pi$ ) (Zhilin, 2004). The resulting effect is amplified by a more complicated strategic management system, according to higher strategic goals, enhanced resources and competencies. This, in turn, determines the necessity and possibility of expanding the company's SSR beyond its management and involving the subordinate initiative owners in the process of balanced enterprise management. The search for appropriate mechanisms, including non-traditional ones, such as the procedure/methodology of eventological scoring (e-scoring), is becoming an urgent issue. Eventology is a scientific concept of the influence of events on the mind and matter; it reveals general and eventual patterns inherent in the mind and matter in all event manifestations and properties (Vorobyev, 2006). From the standpoint of eventology, subjective observations and the mathematical apparatus of the theory of random events allow identifying the general statistical regularities in the distribution of the probabilistic set in various systems, including management systems. Examples of the use of eventological methods in management are: evaluating the creditworthiness of borrowers in the banking system, optimization of securities portfolio risks, customer assessment in the system of retail and wholesale trade. The existing practice of using eventological methods to give numerical values to nonfinancial indicators and metrics of unidentified intangible assets (Yerokhina, 2013; Satsuk, 2010) should be extended to: selection, structuring and balancing of KPIs; selfdiagnostics of the strategic potential of the enterprise in the process of monitoring the achievability of the strategy and its relevant corrections. From the standpoint of the balanced approach, the need to enrich the BSC methodology by the methods of eventological analysis is boosted by the need to take into account the growing number of random, diverse and seemingly unrelated factors in the process of managing.

\section{BSC methodology as a balanced enterprise management system}

The structural-logical model of the BSC methodology as a system of balanced enterprise management is represented in Figure 2. The methodology of the BSC as a balanced enterprise management system combines techniques and technologies of interrelated structural elements of the strategy management: from defining the strategy to detecting its "bottlenecks" through monitoring the level of managerial excellence, with a subsequent self-assessment diagnostics of the enterprise's strategic potential and assessing its adequacy for the implementation of the Strategic Management Improvement Script, followed by relevant corrections of the strategy and balanced scorecard.

\section{Formation of the management panel of indicators using the methods of e-scoring and analytic hierarchy process}

We consider the methodology of the BSC (balanced enterprise management system based on the BSC) as a system involving: traditional methods and technologies of the BSC (cascading, decomposition, etc.); traditional methods and technologies of strategic enterprise management (managerial, financial and economic diagnostics, Script analysis, brainstorming, etc.); and non-traditional methods of eventological analysis and analytic hierarchy process.

The core stage in creating a managerial panel of enterprise indicators is the selection, structuring and balancing of the KPIs. The list of the main criteria for selecting the KPIs for the management panel (strategic orientation and efficiency, functionality, balance of interests of the subjects of management, the possibility of cascading, ease of calculation, motivation and profitability) is subordinated to the task of their cobalancing, ranking them in importance and determining their interdependence to create the top-management panel using the methods of e-scoring and analytic hierarchy process. The $I_{33}$ indicator balance index is used for a quantitative evaluation of the balance; it is calculated by the method of e-scoring as a conditional probability of the target event $s$ - "the strategic indicator is generally balanced with the management panel indicators" in the conditions of the occurrence of a certain combination of the questionnaire events.

E-scoring allows integral evaluation of a targeted event occurrence on the basis of a probabilistic distribution set of the questionnaire questions (Vorobyov, 2004; Vorobyev, Goldenok, 2003; Sherykalova, 2010). According to the existing method, if the estimate of the probability of the event under consideration is performed within the framework of a probability space: $(\omega, F, P)$ with the algebra: $F$ of events measured and probability: $P$, then all the set of events: $X$ being analysed will be considered as measured relative to algebra $F$, i.e.: $X \subset F$; $\omega$ is the space of elementary target events.

According to the method of e-scoring, the basic difference between the questionnaires for the target group of experts in comparison with the experts' evaluation is the formulation of a questionnaire containing closed questions and binary responses. The purpose of the survey is to assess the probability of the target event. Events are divided into two groups: elementary events: $x_{i} \subseteq \omega$ are events formulated in the questionnaire questions, and questionnaire events: $£ \subseteq \omega$ - events that are modelled by respondents in the process of their answers to the questionnaire. Using the questionnaire survey, one can estimate the probability of the occurrence of the target event $s$ based on the relationship between the elementary event: $x_{i} \subseteq \omega$ and the questionnaire event: $£ \subseteq \omega$. A set 


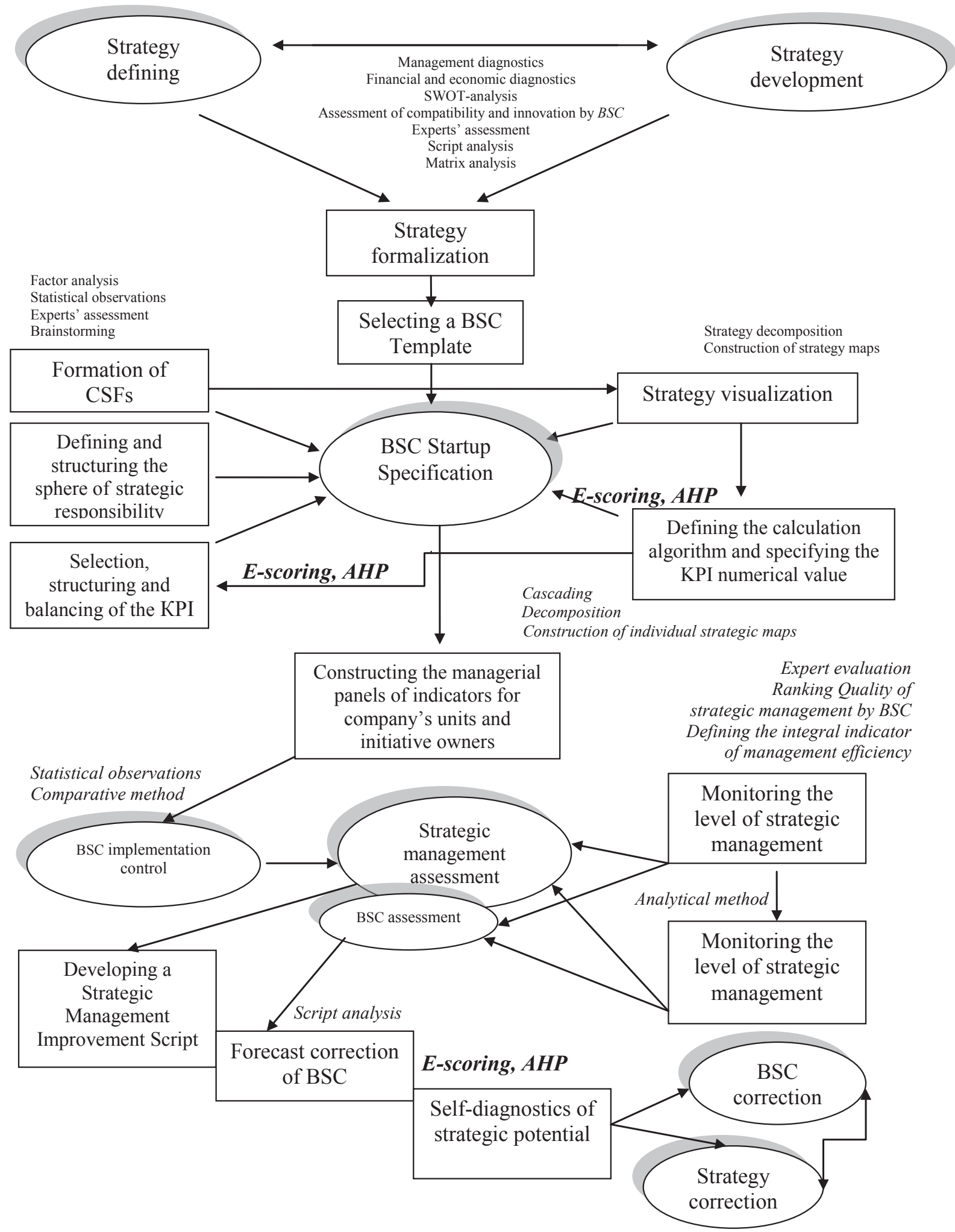

Figure 2. Structural-logical model of the methodology of the BSC as a system of balanced enterprise management

of experts evaluating the state of the research object is $M=\{\eta, \lambda, \ldots, v\}$. In accordance with the e-scoring method, the set $X$ is considered as the set of elementary probable events, in which each question of the questionnaire about the factor: $x_{i}(i=1, \ldots, n)$ can be represented as $x i=\left\{x_{1}, x_{2}, . ., x_{n}\right\}$, where the $k$-th variant is the answer to the question $x i$, which represents a certain level of the value of the factors: $x_{i}\left(k=1, \ldots, p_{i}\right)$. In this case, events with a fixed 
$\mathrm{k}$ can have a different structure of dependence, therefore, the set $\left\{x_{1}, x_{2}, \ldots, x_{n}\right\}$ also has a certain structure of dependence. Statistical processing of the questionnaires gives the frequencies: $p(j, 0)$ and $p(j, 1)$ of the experts' giving positive or negative answers, respectively, to $j$-th question (statistical probability of a specific elementary event). For statistical processing and subsequent interpretation of the survey results according to majority rule, the method of e-scoring analysis uses the parameter: $a=0.5$ (if the frequency of the experts' positive answers to a question of the e-scoring questionnaire is higher than or equal to 0,5 , then the experts' response is considered to favour the target event and vice versa).

The e-scoring technique imparts a positive weight: $\omega(s \cap x) \geq 0$ and $\omega\left(s^{c} \cap x\right) \geq 0$ to the elementary event $\mathrm{x}$, both favourable and unfavourable for the event s. A probable interpretation of this weight takes the following form:

$$
\begin{aligned}
& \omega(s \cap x) \approx P(s \cap x)=P(s \mid x) P(x), \\
& \omega\left(s^{c} \cap x\right) \approx P\left(s^{c} \cap x\right)=P\left(s^{c} \mid x\right) P(x)
\end{aligned}
$$

To define $I_{33}$, the tool apparatus of e-scoring is used: a formula for calculating the conditional probability of the target event $s$ in the occurrence of a specific combination of the questionnaire events, modelled by experts in the process of their answering the questionnaire. In this case, the event takes into account the features of the 3 possible eventological structures of the elementary events (formulated in the questions of the questionnaire): least intersecting, independent and embedded. Thus, the conditional probability: $P\left(s \mid t_{s}^{\cup}(X)\right)$ is calculated for the target event $s$ in the occurrence of a specific combination of questionnaire events interpreted as a terrace event: $t(X) \subseteq \omega$ for alternative eventological structures of the elementary events. For the least intersecting events, the calculation is carried out according to the formula:

$$
P\left(s \mid t_{s}^{\cup}(X)\right)=\frac{\sum_{x \in X} \omega(s \cap x)}{\sum_{x \in X} \omega(s \cap x)+\sum_{x \in X^{c}} \omega\left(s^{c} \cap x\right)},
$$

where $\omega$ is the space of elementary target events $s ; x$ is a set of selected factors characterizing the state of the object of analysis and represented in the questionnaire; $X$ is a set of basic criteria of balance, which are reflected in the questionnaire;

$\omega(s \cap x)$ is the results of the interpretation of questionnaire events-answers as positive responses, contributing to the target event; $\omega\left(s^{c} \cap x\right)$ is the results of the interpretation of questionnaire events-responses as negative; $c^{s}$ is a complement to the target event s.

Hence, ignoring the level of importance of the selection criteria, index of the balance of each BSC indicator: $I_{3}$ is:

$$
I_{3}=P\left(s \mid t_{s}^{\cup}(X)\right) \text {. }
$$

The proposed questionnaire for an e-scoring analysis of the KPI balance in a value-oriented enterprise is presented in Table 1 . In order to obtain a more objective assessment of the level of balance of each of the indicators to be included in the BSC, the calculation of $I_{33}$ uses weighing coefficients $\left(r_{3 i}\right)$, which measure the importance of the KPI selection criteria on the basis of the AHP mathematical tools.

There are $X$ criteria that justify the selection of indicators to the BSC, and each criterion has a different level of importance. Experts should compare the criteria pairwise using the scale of preference (Table 2).

The pairwise comparison of the importance of criteria to be used for the selection of indicators to the BSC produces an inverse-symmetric matrix $\mathrm{A}$, which has the form:

$$
A=\left|\begin{array}{cccc}
1 & a_{12} & \ldots & a_{1 j} \\
a_{21} & 1 & \ldots & a_{2 j} \\
\ldots & \ldots & \ldots & \ldots \\
a_{i 1} & a_{i 2} & \ldots & 1
\end{array}\right|,
$$

where $a_{i j}$ is the criterion degree of preference, defined using the scale of preferences. Note that: $a_{j i}=1 / a_{i j}$.

The expert-generated matrix of pairwise comparisons $A$ is the basis for the calculation of the corrected matrix $A_{C}$, whose elements are calculated by the formula:

$$
c_{i j}=\frac{a_{i j}}{\sum_{i=1}^{k} a_{i j}} \text {. }
$$

Table 1

Questionnaire for e-scoring analysis of KPI balance

\begin{tabular}{|c|l|l|}
\hline $\begin{array}{c}\text { Question } \\
x\end{array}$ & \multicolumn{1}{|c|}{$\begin{array}{c}\text { Main criteria for selection } \\
\text { of indicator }\end{array}$} & \multicolumn{1}{|c|}{ Elementary events $(x i \subseteq \omega)$ - events, formulated in the questions of the questionnaire } \\
\hline 1 & Strategic orientation and efficiency & Is it possible to assess the degree of implementing the enterprise's strategy using the indicator? \\
\hline 2 & Functionality & $\begin{array}{l}\text { Can a strategic initiative owner really influence the results of using the company's potential } \\
\text { or activation of its growth potential by reaching the indicator metric? }\end{array}$ \\
\hline 3 & Balance of interests & $\begin{array}{l}\text { Does reaching the indicator metric increase the enterprise's value in the opinion of } \\
\text { different consumers of information? }\end{array}$ \\
\hline 4 & Possibility of cascading & $\begin{array}{l}\text { Does achieving the indicator affect the performance of other levels of management and } \\
\text { other owners of strategic initiatives? }\end{array}$ \\
\hline 5 & Ease of calculation & $\begin{array}{l}\text { Does the initiative owner understand the algorithm of calculating the indicator or the way } \\
\text { of making a specific decision based on a text description of the indicator? }\end{array}$ \\
\hline 6 & Degree of motivation & Does the indicator serve to achieve strategic goals? \\
\hline $\mathrm{X}_{7}$ & Economy & Does the enterprise have an information base for calculating the indicator? \\
\hline & &
\end{tabular}


Table 2

The scale of preferences for the criteria of indicator selection

\begin{tabular}{|l|c|l|}
\hline Degree of preference & Score in points & \multicolumn{1}{|c|}{ Explanation } \\
\hline Equally preferred & 1 & The two criteria are rated equally important for the selection of indicators for the balanced scorecard. \\
\hline Moderately preferred & 3 & $\begin{array}{l}\text { There is a slight preference of the first criterion to the other in selecting indicators for the } \\
\text { balanced scorecard. }\end{array}$ \\
\hline Medium preference & 5 & The importance of the first criterion has a medium advantage over the other. \\
\hline Strongly preferred & 7 & The importance of the first criterion significantly exceeds the importance of the other. \\
\hline Absolutely preferred & 9 & The first criterion in terms of importance is absolutely preferred to the other. \\
\hline Intermediate values & $2,4,6,8$ & Applied, if a compromise solution is needed to determine the importance of a criterion. \\
\hline
\end{tabular}

The data of the matrix $A_{C}$ are used to define a vector of weighing coefficients of the criteria for selecting indicators for the balanced scorecard $r_{j}$ :

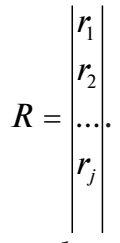

Each of the weighting coefficients is calculated according to the formula:

$$
r_{3 j}=\frac{\sum_{j=1}^{k} c_{i j}}{k},
$$

where $k$ is the number of criteria to be used for the selection of indicators to the balanced scorecard.

Thus, vector $\mathrm{R}$ determines the importance of each criterion used to justify the selection of an indicator to the BSC. In order to verify the correctness of the matrix $A$ design and subsequent calculations, it is necessary to determine the consistency ratio (Saati, 1993):

$$
B \Pi=\frac{I_{I I}}{I_{B}},
$$

where $I_{\Pi}$ is consistency index; $I_{B}$ is random index.

The random index depends on the number of criteria used for the selection of indicators to the balanced scorecard. The consistency index is calculated according to the formula (Saati, 1993):

$$
I_{\Pi}=\frac{\Pi \Pi-k}{k-1}
$$

where $\Pi \Pi$ is a consistency estimator, which is defined by the expression:

$$
\Pi \Pi=\sum_{j=1}^{k} \sum_{i=1}^{n} a_{i j} \times r_{3 j} \text {. }
$$

If the consistency ratio is less than 0,1 , then the matrix is formed correctly and further calculations will be reliable.

Taking into account the degrees of importance of the criteria used for the selection of indicators, the Balance Index in the BSC for each of them will be calculated according to the formula (in a situation of least intersecting elementary events):

$$
I_{33}=\frac{\sum_{x \in X} \omega(s \cap x) r_{3 i}}{\sum_{x \in X} \omega(s \cap x) r_{3 i}+\sum_{x \in X^{c}} \omega\left(s^{c} \cap x\right) r_{3 i}} .
$$

Similarly, the formula for calculating $I_{3}$ is modified, and the corresponding balance index $I_{33}$ for other eventological structures is defined.

The calculated $I_{33}$ allows assessing thelevel ofbalance of each indicator (close to or greater than: $\alpha=0,5$ ) and the validity of its inclusion in the BSC: high balance $\left(I_{33} \geq 0,7\right)$, average balance $\left(0,5 \leq I_{33}<0,7\right)$ and low balance $\left(I_{33}<0,5\right)$. It is also possible to determine the highest priority indicators and lagging metrics.

The balance index of the entire system of indicators, which takes into account the degree of importance of each criterion to be used for the selection, will be:

$$
I_{3 a 2}=\frac{\sum_{i=1}^{n} I_{33_{i}}}{n},
$$

where $n$ is the number of indicators selected for the BSC using the main selection criteria, $i=1,2 \ldots n$.

\section{Self-diagnostics of strategic potential of the enterprise by the e-scoring method}

A prerequisite for the effective formation of balanced enterprise management is the adequate level of strategic potential of the company, its intellectual capital as the main source of growth of its market value. The existing level of strategic potential may be quite sufficient for implementing one type of valueoriented strategy but insufficient for another. This requires self-diagnostics of the company's strategic potential. Unlike controlling, self-diagnostics involves the staff, each employee of the enterprise in the process of strategy management based on the proposed methodological approach to assessing the strategic potential of the enterprise, which includes defining an intellectual potential index that takes into account the level of importance of the criteria used to assess the strategic potential through a combination of eventological scoring methods and analytic hierarchy process.

The questions in the proposed questionnaire for e-scoring analysis of the company's strategic potential (Table 3) cover various aspects of the qualitative level of intellectual capital of the enterprise as the basis of its strategic potential. 
Vol. 4, No. 5, 2018

Table 3

Questionnaire for e-scoring analysis of self-diagnostics of intellectual potential of enterprise (fragment)

\begin{tabular}{|c|c|}
\hline$x i$ & Elementary event $x i \subseteq \omega$ \\
\hline \multicolumn{2}{|r|}{ Management Capital } \\
\hline $\mathrm{x}_{1}$ & Indicators of annual budgets are real and aimed at achieving operational financial goals \\
\hline $\mathrm{x}_{2}$ & We feel the effectiveness of managerial decisions \\
\hline $\mathrm{x}_{3}$ & We know our competitive advantages \\
\hline $\mathrm{x}_{4}$ & Our operational activities are subject to the achievement of strategic goals \\
\hline $\mathrm{x}_{5}$ & $\begin{array}{l}\text { The organizational structure of the management allows prompt response to changes in the internal and external } \\
\text { environment }\end{array}$ \\
\hline $\mathrm{x}_{6}$ & Regular analysis of the implementation of the plans is carried out \\
\hline $\mathrm{x}_{7}$ & We appreciate the management style of senior officers \\
\hline $\mathrm{x}_{8}$ & The management of the enterprise has the necessary level of professionalism and creativity \\
\hline $\mathrm{x}_{9}$ & $\begin{array}{l}\text { The enterprise has many levels of management that slow down the timely and reliable communication of information to the } \\
\text { lower levels of management. }\end{array}$ \\
\hline $\mathrm{x}_{10}$ & We respond promptly to the problems faced by customers \\
\hline $\mathrm{x}_{11}$ & We thoroughly analyse the results of the implementation of current plans throughout the year \\
\hline $\mathrm{x}_{12}$ & We have a clear understanding of our place in the enterprise management system \\
\hline $\mathrm{x}_{13}$ & We set only real goals for ourselves \\
\hline $\mathrm{x}_{14}$ & Plans of our management are always co-balanced \\
\hline $\mathrm{x}_{15}$ & Our material remuneration depends on the achievement of strategic goals \\
\hline \multicolumn{2}{|r|}{ Information Capital xi $(i=16, \ldots, 25)$} \\
\hline $\mathrm{x}_{16}$ & The information system of the enterprise is only focused on accounting, and not on an individual information consumer \\
\hline \multicolumn{2}{|r|}{ Human capital $x i(\mathrm{i}=26, \ldots, 40)$} \\
\hline $\mathrm{x}_{26}$ & We are aware of real opportunities to show our skills and abilities and make a good career \\
\hline \multicolumn{2}{|r|}{ Organizational capital $x i(\mathrm{i}=41, \ldots, 50)$} \\
\hline $\mathrm{x}_{41}$ & Achievement of strategic goals is our priority \\
\hline
\end{tabular}

The assessment is carried out by designated respondents, who are experts from the production and management units of the enterprise. The conditional probability of the occurrence of the elementary event $\mathrm{s}$ is estimated: "the necessity and possibility of establishing balanced enterprise management," i.e., the integration of BSC into the system of strategic enterprise management. Elementary events $x_{i} \subseteq \omega$, which are the events formulated in the questionnaire, are grouped according to the structure of intellectual capital of the enterprise as the basis of its strategic potential. Calculation of the conditional probability of the target event $s$ in the situation of the least intersecting elementary events allows determining the index of intellectual potential $I_{i n}$, which takes into account the importance of the assessment criteria by the formula:

$$
\operatorname{Ii} \Pi=\frac{\sum_{x \in X} \omega(s \cap x) r_{3 i}}{\sum_{x \in X} \omega(s \cap x) r_{3 i}+\sum_{x \in X^{c}} \omega\left(s^{c} \cap x\right) r_{3 i}},
$$

where $r_{3 i}$ is the weighing coefficient or the degree of importance of the $i$-th criterion for assessing the intellectual capital of the enterprise according to its characteristics/structural components; $i=1,2 \ldots 50$.

The strategic potential of the enterprise is considered sufficient for the implementation of balanced enterprise management if in the index of intellectual potential is within the interval: $I_{\text {in }}=\{0,5 ; 1\}$.
According to the proposed BSC methodology, selfdiagnostics of the company's strategic potential, based on a combination of methods of e-scoring and AHP allows identifying the main problems and factors of increasing the value/level of the analysed object, which is done through analysing the questionnaire events (responses) interpreted as those that do not contribute to the occurrence of the target event - the desired level of enterprise management.

\section{Conclusions}

The BSC methodology as a balanced enterprise management system combines the techniques and technologies of interrelated structural elements of strategy management: from defining the strategy to identifying its "bottlenecks" through the procedure for monitoring the level of management excellence, the subsequent self-diagnostics of the enterprise's strategic potential and assessing its adequacy for implementation the Strategic Management Improvement Script, followed by the relevant corrections of the strategy and balanced scorecard. Integration of e-scoring with the BSC method ensures the effective functioning of vertical communication as the basic principle of balanced enterprise management, extending the scope of strategic responsibility to subordinate owners of initiatives. The proposed methodical approach to balancing and structuring the KPIs, based on the results of eventological analysis and analytic hierarchy process, 
enables achieving the established level of the balance of indicators taking into account the weighting factors of the major selection criteria; it allows determining the balance index of the whole system as the average of the balance indices of each of the indicators characterizing the enterprise performance. The extension of the subject field of the eventological analysis and analytic hierarchy process to the assessment of the company's strategic potential makes it possible to turn BSC into a "working model" for managing the enterprise strategy.

\section{References:}

Ashworth, G., Dzhejms, P. (2006). Menedzhment, osnovannyj na cennosti: Kak obespechit cennost dlja akcionerov [Value-Based Management: How to Provide Value to Shareholders]. Moscow: INFRA-M. (in Russian)

Ivakina, I. (2007). Zbalansovana systema pokaznykiv [Balanced Scorecard]. Kharkiv: Faktor. (in Ukrainian)

Martin, Dzhon D., Petti, Viljam Dzh. (2006). VBM - upravleniye, osnovannoye na stoimosti. Korporativnyy otvet revolyutsii aktsionerov [Value Based Management: The Corporate Response to the Shareholder Revolution]. Dnepropetrovsk: Balans Biznes Buks. (in Ukrainian)

Saati, T. (1993). Prinyatiye resheniy. Metod analiza iyerarkhiy [Decision making with the analytic hierarchy process]. Moscow: Radio i svyaz. (in Russian)

Satsuk, T. P. (2010). Postroyeniye sistemy upravleniya finansami organizatsiy na osnove kontrollinga (na primere torgovykh setevykh kompaniy) [Construction of a financial management system for organizations based on controlling (by an example of trading network companies)]. (PhD Thesis), Sankt-Peterburg. Retrieved from: oldvak.ed.gov.ru/common/img/uploaded/files/.../2010/.../SatsukTP.do

Sherykalova, M. I. (2010). Metod eventologicheskogo skoringa dlya sluchaya nechetkogo sobytiya, interpretiruyushchego anketnoye [Method of eventological scoring for the case of a fuzzy event that interprets the questionnaire]. Krasnoyarsk: KGTEI, SFU.

Vorobyov, O. Yu. (2006). Vvedeniye v eventologiyu: uchebnoye posobiye [Introduction to the Eventology: Tutorial]. Krasnoyarsk: IVM SO RAN, KrasGU. (in Russian)

Vorobyov, O. Yu. (2004). Eventologicheskiye struktury i eventologicheskiy skoring [Eventological structures and eventological scoring]. E-zapiski FAM seminara, 8, 73-113. Krasnoyarsk: IVMSORAN. (in Russian)

Vorobyov, Yu., Goldenok, E. and others (2003). Teoriya sluchaynykh sobytiy i eye primeneniye [Theory of random events and its application]. Krasnoyarsk: IVM SO RAN. (in Russian)

Yerokhina, A. V. (2013). Sozdaniye effektivnoy sistemy finansovogo kontrollinga v obshchestvakh s ogranichennoy otvetstvennostyu [Creation of effective financial control system in limited liability companies]. (PhD), SanktPeterburg. (in Russian)

Zhilin, D. M. (2004). Teoriya sistem [Theory of systems]. Moscow: URSS. (in Russian) 